Geochemistry and Cosmochemistry, Proceedings of the 27th International Geological Congress, Vol. 11, Moscow 4-14 August 1984, N. A. Bogdanov (Gen. Sec. Organizing Cte.). VNU Science Press. 1984, 605p.. DM 164.00.

ANOTHER IGC HAS passed and a flood of proceedings volumes (23 in all) are appearing. There are a number of excellent papers in Volume 11 aimed at an informed readership, that outline the dramatic progress made over the past few years in understanding the chemical origins and evolution of ter restrial and meteoritic systems.

Regretably the editor's pen has been lightly exercised in the correction of constituent manuscripts, particularly with respect to Russian and Japanese contributions and a resulting unevenness in presentation format and figure quality is present. Despite these problems, the volume is recommended reading. given the quality of some of the reviews and the possibility that ideas presented in other papers will prove influential in further research.

Space permits selection of only a few of the 29 papers for special mention. Leading this list is a delightfully succinct summary by $G$. J. Wasserburg of the constraints provided by the known presence of various short-lived radioactive nuclei in the early solar system (ESS) for nucleosynthetic events and timing of planetesimal formation. The intriguing variety of processes extant in the ESS and recorded in chondrules are described by $G$. Kurat and include fractionation of alkalis, vapor, siderophiles and metal from silicate. together with melting and agglomeration.
Terrestrial studies are led by $M$. Ozima and $\$$. Zashu who document the dramatically high ${ }^{3} \mathrm{He} /{ }^{4} \mathrm{He}$ tatios of some diamonds, apparently representing a trapped early solar wind fraction resulting from deuterium burning. Two studies address the problems of secular evolution of the Earth's crusi (J. VEIzER and A. B. RONOV ef al.) in both of which the significance of superimposed recycling on one-way chemical differentiation is emphasized. Discussion of the heterogeneit of redox conditions (M. SATO) and the abundances, chemical form. and isotopic variation of potential volatile species $(H$. He. $C$ and N) (S. MatSUO) are useful contributions to the ongoing debate concerning volatile interactions and evolution in the Earth"s interior. The degree of exchange between global geochemical reservoirs via convective processes is addressed by $\mathrm{D}$. Turcotte. and the continuing saga of fingerprinting the isotopic reservoirs and mantle fractionation events is augmented by $M$. Tatsumoto and colleagues. Finally in this atbreviated list. the concise summary of the role of accessory minerals in felsic magma evolution by E. B. Watson and T. M. Harrison deserves a wide readership.

Overall then, a stimulating diversity of topics can the dis covered in these Proceedings, and they are well worth seck ing out.

Department of Geological Sciences

Richard Arculu

The University of Michigan

Ann Arbor. MI 48109-1063

I.S.A
Comparative Planetology, Proceedings of the 27th International Geological Congress, Moscow, 1984, N. A. Bodganov (Gen. Sec.). VNU Science Press. 1984. 288 p. DM 113.00

IN THIS COMPENDIUM of twenty papers, V. L. Barsukov and A. T. Basilevsky consider comparative planetology as the "comparative geology of the planets and satellites, provided the term geology is used in its broad sense". This is a subject of considerable range and interest, as evidenced by the inclusion of papers on various aspects of martian evolution (4). the moon (2), the early earth (3), impact phenomena (5), and the origin of life (5). Many of these papers are obviously intended to be summaries and have such encompassing titles as Tectonics of Mars and Chemical Studies of the Origin of Life.

With an international authorship, it is laudable that all the papers are in English. Unfortunately, in some cases, this leads to awkward or confusing phraseology and to the introduction of typographical errors in the camera-ready text. The papers lack uniformity in format and organization. Many have no abstract, tables are few and far between, figures are of variable quality and appear within and at the end of papers. and one contribution has no references. Conspicuous by its absence is any imagery, which is a mainstay of many planetary studies.

This volume exemplifies differences in acceptable writing style and format in the international community. That is not to say that some of the discussions are not interesting. I enjoyed reading the papers on the Origin of Life, which is obviousiy still controversial. This, however, was tempered by finding a discussion on the Geologic Map and Optical Properties of the Near Side of the Moon included amongst the group of Origin of Life papers. In shor, this volume is not easy to read and cries out for good technical editing. Although I contributed to this book, 1 have dificulty in deciding who would truly benefit from having it on their personal bookshelves. Personally, 1 find comparative planetology an interesting and increasingly important subject and hope the technical problems with this book, and other Proceedings volumes, will not be repeated in the Proceedings of the 28th International Ger. logical Congress.

\section{Geological Survey of Canada}

R. A F. Grieve
Energy. Mines \& Resources
Ottawa. Ontario KlA $0 Y 3$

Canada 